\title{
LAS PESADILLAS DE SHANGO: LOS "ASESINATOS CONSTANZO” DE MATAMOROS EN EL CINE
}

\author{
Robert Harland
}

\begin{abstract}
RESUMEN
El artículo examina dos películas inspiradas por los asesinatos cometidos por Adolfo de Jesús Constanzo, los cuales tuvieron lugar en Matamoros y el Distrito Federal de México en los años 80, más notoriamente en 1989 cuando se sacrificó al estudiante estadounidense Mark Kilroy. Constanzo empleó una mezcla particular y repugnante de las religiones afro-hispanas, santería y palo mayombe para realizar sus asesinatos rituales y controlar a sus seguidores. Los dos largometrajes son Perdita Durango (1997) de Alex de la Iglesia, y Borderland (2007) de Zev Berman.

Palabras clave: cine de la frontera, Alex de la Iglesia, Zev Berman, santería, horror.
\end{abstract}

\begin{abstract}
The article examines two films inspired by the Adolfo de Jesús Constanzo murders, which took place in Matamoros and in Mexico city in the 1980s, most notably in 1989 when he sacrificed the American student Mark Kilroy. Constanzo employed an odd and repellant mix of the Afro-Hispanic religions, santería and palo mayombe to carry out his ritual murders and control his followers. The two films are Perdita Durango (1997) by Alex de la Iglesia, and Borderland (2007) by Zev Berman.

Key Words: border cinema, Alex de la Iglesia, Zev Berman, santería, horror.
\end{abstract}

\section{Introducción}

Cuando vi la película de Alex de la Iglesia Perdita Durango (también conocido como Dance with the Devil [Baila con el Diablo] en mercados anglohablantes) en la televisión británica su mezcla de inglés, español, sexo y violencia me gustó. Cuando la vi otra vez después de haber vivido en la frontera por un tiempo, ciertas partes me preocuparon, otras me

Dr. Robert Harland. Profesor. Departamento de Lenguas Extranjeras. Mississippi State University. Correo electrónico: rob_mla@yahoo.com

Recepción: 15- 12- 2009

Aceptación: 21- 01- 2010 
parecieron falsas, y otras simplemente mal hechas a pesar de cierta calidad en su producción. Y así me quedó en la mente. Pero lo que no sabía entonces es que el cliché "basado en hechos reales" (una frase que no parece en la lista de créditos de esta película) sí que es verdad en este caso. Y ahora se han hecho dos películas sobre los hechos, los asesinatos originales siendo obra de Adolfo de Jesús Constanzo, un hombre que se mezclaba con los narcotraficantes y cruzaba fronteras con suma facilidad, y quien sembró docenas de cadáveres sacrificiales entre el D.F y Matamoros. Tampoco habría podido sospechar que la segunda versión cinematográfica de los hechos se realizaría en el 2007: el magnífico Borderland / Tierra fronteriza (Berman 2008).

Constanzo era cubano-americano. Nació en Miami, y su madre lo inició en la religión de santería, creyéndole dotado de poderes proféticos. Si hubo una presencia paterna en su vida, fue la de un sacerdote de vudú haitiano, y de él Constanzo no sólo aprendió los ritos de esta religión sino también cómo emplearla como fuente de dinero al obtener como clientes a los mafiosos que buscaban ayuda sobrenatural para sus actividades criminales. Mientras tanto su atractivo físico le permitió ejercer el trabajo de modelo. Este empleo le llevó al D.F. y allí empezó su carrera como sacerdote santero independiente, con varios discípulos, amantes de ambos sexos, y seguidores adinerados. Los integrantes de su círculo consistían en narcotraficantes pero también incluían actrices, hombres de negocios y policías de altos cargos. Constanzo afirmaba su necesidad de víctimas sacrificiales para su nganga (caldera sagrada) y sus seguidores los obtenían; él entonces los mataba ritualmente. El santero se involucró personalmente en negocios ilegales transfronterizos, extendiendo sus operaciones criminales hasta Matamoros, donde también practicaba sus ritos sangrientos, y eligió a Sara Aldrete como sacerdotisa de su secta. Aldrete era una estudiante sobresaliente de nacionalidad mexicana, integrante de las listas de honor en su escuela, quien estudiaba (entre otras cosas) antropología en Southmost Texas College de Brownsville. Dividiendo su tiempo entre la frontera y el Distrito Federal Constanzo continuó su carrera criminal con la ayuda de Aldrete y otros discípulos. Finalmente, su elección desafortunada de una víctima estadounidense anglosajón -Mark Kilroy- desencadenó la ola de publicidad y una investigación seria que resultaron en el suicidio de Constanzo en la ciudad de México. Su muerte también estuvo llena de detalles extraordinarios ya que fue acompañada del suicidio de un compañero y las dos vidas fueron tomadas por otro discípulo quien siguió las instrucciones de Constanzo y causó la muerte de ambos bajo las órdenes expresas del cubano-americano. El escándalo estalló en los periódicos y la televisión de entonces pero ha perdurado hasta la fecha (Provost 1989; Newton s.f.; Land, Weisfeld 2008; Applebome 1989; Associated Press 1989).

La combinación de múltiples temas morbosos: sexo, asesinato, ritos supuestamente satánicos y cuestiones de cultura y etnia es, claramente, una fórmula que el cine ha aplicado desde el principio de las películas de horror. Inicialmente el género se enfocó en el vudú de zombis haitianos en lugar de ocuparse de temas relacionados con la santería (más hispana; el vudú pertenece a las culturas afroamericanas de habla francesa aunque los orígenes son muy parecidos). Entre esas primeras producciones se incluye un rango de producciones que va desde White Zombie / El zombie blanco con Bela Lugosi (Halperin 1932) hasta The Serpent and the Rainbow / La serpiente y el arco iris (Craven 1988), con la posibilidad de que se diera la ocasión de integrar algún giro satánico como es el caso de Angel Heart / Corazón de Ángel (Parker 1987). En muy pocas ocasiones los directores que explotan este género han dado muestra de respetar la cultura que produjo esta religión: aunque existen excepciones. La magnífica I Walked with a Zombie / Caminé con una zombi (Tourneur, 1943) y (tal vez) The Serpent and the Rainbow son muestra de que es posible tratar el tema integrando una 
visión más compleja. Ya que generalmente el morbo triunfa sobre la cultura, la historia cinematográfica recurrente es la del extranjero (británico o estadounidense) obligado a enfrentarse con el horror no sólo de una religión desconocida y terrorífica, sino también con lo extraño, con un Otro bárbaro y repugnante al que se le compara con la ciencia y religión occidentales, más racionales y puras -supuestamente-.

La santería, como el vudú, se deriva del politeísmo de los esclavos de África del Oeste, mezclado con el catolicismo cuyos santos (sobre todo sus estatuas) servían de máscara para los dioses de sus antepasados. Los esclavos podían de esta manera seguir practicando su religión al trasladar las figuras de sus dioses a las de los santos impuestos por las autoridades eclesiásticas de los imperios europeos. Sin embargo, hay que hacer notar que la santería no tiene un carácter satánico. Aunque se practica el sacrificio de animales esto es relativamente inofensivo, sobre todo cuando uno recuerda que la religión de los esclavistas de origen europeo muchas veces servía de excusa para practicar la esclavitud.

Como otras religiones, la santería ha seguido un proceso social que implica el sincretismo natural no sólo con el cristianismo, sino también con otras religiones africanas. En su estudio sobre la santería, Migene González-Whippler explica que ésta proviene de la religión de los yoruba (un pueblo de la costa africana occidental originalmente asentado en ambos lados del río Niger). González-Whippler describe el palo mayombe o palo monte como el precursor de la santería y un tipo de "Magia negra: brujería" por lo que utiliza tal término para titular su capítulo (1990: 129-138). Aunque la santería se remonta a la comunidad yoruba, González-Whippler admite que sus practicantes no provienen de este pueblo, sino que son miembros de otros grupos africanos, los bantúes y los congos. Éstos son los que utilizan los conjuros con la ayuda de su nganga, con la intención de obtener beneficios aun a costa de causar daño a otras personas.

No obstante, la santería no es tan sencilla de rastrear y definir. Según las etnólogas Natalia Bolívar Aróstegui y Carmen Gónzalez Díaz de Villegas palo mayombe (también a veces palo monte; el sustantivo y adjetivo es palero) y su cuerpo de creencias y rituales es otra religión enteramente. Traída al continente Americano por los esclavos de la región del río Congo el palo mayombe no es brujería ni satanismo. Bolívar Aróstegui y Gónzalez Díaz de Villegas identifican dos ramas distintas, la buena y la mala, y en el sistema original del palo monte el espíritu sólo funciona en ambos casos debido a la sabiduría del sacerdote, no a prácticas morbosas en sí. No obstante,

\footnotetext{
[m]uchos informantes, para dramatizar el alcance de sus fuerzas espirituales, cuentan de sus prendas [ngangas] leyendas aterradoras. Afirman que están fundamentadas con las krillumbas de asesinos, de muertos por violencia, de locos y que por ello les ofrendan gatos negros y las cimbran a medianoche. Insisten en que sus prendas trabajan con los espíritus buenos o malos que están cerrados en ellas, según el objetivo que se propongan. Pero, en realidad, el espíritu con que se monta una prenda es uno solo y obedecerá sin discusión el mandato de su dueño sólo si éste sabe darle las órdenes pertinentes en lengua, usar los cantos adecuados [...etc.]. (Bolívar y González, 1998: 60)
}

Entonces la opinión de González-Whippler (1990) se debe a una perspectiva de forastero, mezclada con con una tendencia entre unos "sacerdotes" paleros a exagerar sus poderes morbosamente. Schutze tiene una visión de la palo mayombe algo más sensacionalista y morbosa (116-126), más interesado en el asesinato ritual, los misteriosos abakuas (paleros especialmente violentos quienes practican el sacrificio humano) y la relación entre sacerdote brujo y su cliente. Pero su libro pertenece al género true crime [crimen verdadero]. Y en ese mercado hay que vender. 
De hecho, Constanzo fue un ejemplo extremo de este tipo de alarde morboso de palo mayombe aliado a un sincretismo personal que mezcló vudú, santería y palo mayombe sin discriminar entre las religiones, y empleó todo su talento para dar toques teatrales grotescos, asquerosos y desgraciadamente fascinantes a sus ritos. Un ejemplo de esta confusión sincrética que se ha trasladado a ambas películas es el uso del nombre de Chango o Shango en los ritos del "sacerdote", personaje que se basa en Constanzo. Chango / Shango no es un dios mayombero. El panteón al que pertenece esta deidad es de santería . La práctica de palo mayombe tampoco implica obtener huesos humanos por medio de asesinato (ni santería tampoco, aunque recientemente palo mayombe se ha vinculado con robos de tumbas en Venezuela -Romero; McGowan-) ${ }^{1}$. Sin embargo, en las dos películas el sacrificio humano forma parte de los ritos, siguiendo de su manera este aspecto terrorífico de los crímenes verdaderos de Constanzo. Sólo la más reciente, Borderland, tiene una buena santera, Lupe, la dueña de una botánica, para explicar a los personajes (y al espectador) que la religión no es así, que los criminales en este caso actúan de modo tan desalmado porque no creen que tienen alma para perder etc. (supongamos que en su caso la religión es santería, aunque no se dice explícitamente).

Otro problema que existe en la clasificación de la "religión" de Constanzo es la etiqueta comprensible pero cargada de peso cultural que se le atribuye: satanismo. Investigadores y cineastas utilizan el término con el fin de atraer un mayor público. Gary Provost, quien escribió su propio libro sobre los crímenes de Constanzo, Across the Border [Más allá de la frontera] (1989) emplea como parte del título de su libro las palabras "Satanic Cult Killings" [asesinatos rituales satánicos] siendo las más grandes de todas en la cubierta. Jim Schutze titula su libro Cauldron of Blood: The Matamoros Cult Killings [Caldera de sangre: Los asesinatos del culto de Matamoros]. Land y Weisfeld lo llaman the black magic murderer [el asesino de magia negra] más de una vez en su teledocumental Adolfo Constanzo: The Godfather of Matamoros /...El padrino de Matamoros (2008) y en el mismo programa el antropólogo Antonio Zavaleta quien investigó el caso original (con una gran figura de la Virgen de Guadalupe tras él cuando sale en la pantalla) afirma saber que Constanzo tenía un vínculo directo con el Diablo. Al menos Schutze cuestiona esta versión demasiado simple de los hechos (208-210). Desde una perspectiva cultural cristiana puede parecer que esa relación existió así; sin embargo, desde la perspectiva de Constanzo su vínculo se ceñía al mundo hispanoafricano de los espíritus de dioses y muertos. Aparentemente su "fe" fue sincera o por lo menos coherente con su propio sistema de creencias. Y sin embargo, desde una perspectiva santera o mayombera "ortodoxa" sus prácticas contradecían los principios tanto morales como religiosos de los mismos sistemas que Constanzo decía seguir.

Independientemente de la etiqueta que Constanzo y los narradores de su vida decidieran adjudicar a su secta, es necesario separar su figura del contexto "satánico" en el que se le ha colocado hasta ahora. Jeffrey S. Victor en su obra Satanic Panic/Pánico Satánico (1996) encuentra al revisar la historia reciente y lejana que se han propagado una y otra vez rumores de "satanismo". Aunque de hecho no existen prácticas satánicas en los casos que Victor estudió, la diseminación de historias falsas ha sembrado temor y miseria sin razón ninguna. Constanzo fue un ser humano quien creó una mezcla perversa de creencias hispanoafricanas. Los mismos seguidores de las religiones que el asesino afirmó abrazar han rechazado como blasfemia los rituales de Constanzo. Hemos de comprender al hombre en sus propios términos para apreciar el retrato cinematográfico (y también para saber reaccionar con imparcialidad y justicia ante los practicantes de otras religiones en la vida real). 


\title{
2. Perdita Durango
}

No es de sorprender que la historia de Constanzo haya servido como materia productiva para el cine. Hay que recordar que Ed Gein, otro asesino, fue también inspiración de 3 películas de horror de primer rango (Jones 2005: 134, 157; Bell, Beardsley s.f.: 1): Psycho / Psicosis, The Silence of the Lambs / El silencio de los corderos y The Texas Chainsaw Massacre / La matanza de Tejas (Hitchcock 1960; Demme 1991; Hooper 1974). En el caso de Constanzo, el problema es que el director de la primera versión fue el español Alex de la Iglesia con su película Perdita Durango (1997).

Alex de la Iglesia ha dirigido películas en las que logra burlarse de la sociedad española con suma agudeza, pero aquí fracasó. De la Iglesia intentó hacer una película al estilo de David Lynch y (sobre todo) de Quentin Tarantino, con una mezcla de lenguaje soez, ultraviolencia, sexo, y música sugerente en la banda sonora. En la historia del director español se encuentra Romeo Dolorosa (narcotraficante y "santero" caribeño) con Perdita (mexicana hedonista y nihilista). La mujer del título de la película y el caribeño se enamoran para pronto decidir el rapto de dos adolescentes estadounidenses, Duane y Estelle, con el objeto de sacrificar a uno de ellos (crimen que finalmente no cometen). Después de muchas escenas brutales y negocios fracasados, Romeo se dirige estoicamente hacia su muerte, y Perdita, tras de haber liberado a los jóvenes, intenta salvar a Romeo sin éxito.

Perdita Durango casi reproduce exactamente los clichés que Debra Castillo y María Socorro Tabuenca Córdoba notan en la historia del cine fronterizo:

\begin{abstract}
Las mujeres fronterizas eran víctimas de la voluntad del director y / o guiónista, donde los papeles femeninos se limitaban casi exclusivamente a los de "decoración erótica". Por consecuencia, las películas sobre la frontera siempre se definían por unas tramas melodramáticas que se situaban en el mismo número limitado de lugares, y veíamos siempre representaciones cinematográficas de prostitutas, ladrones, macarras, bailarinas exóticas, traficantes de drogas, contrabandistas, o sus antagonistas casi igualmente sensacionalistas: mater admirabilis, prostitutas arrepentidas, o traficantes y contrabandistas rehabilitados. [traducción del autor del párrafo siguiente]
\end{abstract}

\begin{abstract}
Border women were subjected to the male directors' and/or scriptwriters wishes, where women's roles were almost exclusively limited to eye candy. Consequently, movies about the border would always be defined by melodramatic plots set in the same limited locales, and we would always see filmic portrayals of prostitutes, thieves, pimps, exotic dancers, drug dealers, smugglers, or their almost-as-sensational opposites: mater admirabilis, redeemed prostitutes, or rehabilitated dealers and smugglers. (Castillo, Tabuenca 2002: 208)
\end{abstract}

Los dos personajes femeninos en el guión del director español, Estelle y Perdita Durango, son fuertes pero Perdita no es solamente fuerte sino agresiva. Su relación abiertamente sexual con Romeo, su violación de Duane y su habilidad para el baile caben dentro del cliché descrito por Castillo y Tabuenca. En el caso de Estelle, ella es mucho más feliz cuando acepta finalmente su propia sexualidad sin vergüenza.

Perdita Durango incorpora además otro personaje fronterizo cliché, notado por Pablo Vila en sus entrevistas de la vida real. Para Vila "él/la fronterizo/a libertino/a" [sic] (2007: 181-208) es el resultado de una supuesta contaminación social y moral y, por lo tanto, es un ser agringado/a de actitudes bastante tolerantes hacia la sexualidad y el vicio. La existencia de este tipo de personaje se atribuye al estatus de Cd. Juárez y del resto de la frontera como lugar de recreo para adultos estadounidenses. Subrayando su sexo violento y vigoroso Perdita y Romeo con su conversación. Al fondo la música bilingüe, droga y armas de fuego, además de ese 4x4 horriblemente 
personalizado, todos elementos que hacen de Perdita y Romeo el producto demasiado perfecto de los peores aspectos de la frontera.

El filme cumple con su asumido deber de presentarnos el lado oscuro de la frontera de siempre. De hecho Perdita y Romeo combinan ambas "caras" de los personajes fronterizos que Castillo y Tabuenca denuncian como estereotipos negativos: la nobleza con que Romeo va a su muerte y las lágrimas de Perdita que nos demuestran que lo amaba verdaderamente pecan contra del espíritu amoral e irónico de esta película que ni el detalle chistoso de la blancura de los dientes de Romeo Dolorosa puede mitigar. No obstante, caben dentro de los clichés del género.

El problema con esta película es que en muchos casos no se parece a la frontera "real", la que habitan complejos seres humanos y en la que toman lugar procesos sociales también complejos. Aunque De la Iglesia ha satirizado la sociedad española en una variedad de géneros que van desde la ciencia ficción hasta el thriller o incluso el Western, aquí intenta burlarse de una zona con la cual no estaba familiarizado. Tampoco ayuda que apenas emplea a mexicanos en el reparto. Son buenos actores, desde Rosie Pérez como Perdita y Javier Bardem en el papel de Romeo Dolorosa y hasta James Gandolfini entre los secundarios, pero mexicanos no son. En teoría, esto no debería ofender -Anthony Quinn no ganó su Óscar por Zorba el Chihuahuense-, pero aquí falta ambientación cultural, sobre todo en un guión cargado de cambios bruscos y forzados entre el inglés y el español que no suenan naturales; a pesar de que hubo cuatro guiónistas que escribieron el libreto (basado en un libro de Barry Gifford, autor de la novela llevada a la pantalla por David Lynch bajo el título de Wild at Heart), apenas integraron una frase memorable (y la mejor "Don't talk, shoot / No hables, tira" préstamo de El bueno, el malo y el feo de Tuco / Eli Wallach-Leone 1966). Tal vez habría sido mejor simplemente adaptar la historia de Constanzo directamente (hay muchos cambios entre libro y filme), pero el uso de santería, la necesidad de sacrificio para dar de "comer" a la nganga el tráfico de drogas y el rapto de estadounidenses, para luego matarlos ritualmente, deja poco lugar para dudar que Romeo y Perdita son personajes que se basan en las vidas de Constanzo y Aldrete.

La cinematografía es buena, y convierte el desierto en un lugar de amenaza y de sombra perturbadora, pero le falta alma a esta frontera, que en teoría se ubica en Tejas, pero de hecho se filmó mayoritariamente en Arizona, lo que se hace notar a través de los saguaros que se encuentran alrededor del rancho de Romeo: no crecen en otro sitio naturalmente fuera del desierto de Sonora (Anón. "Saguaro Cactus" 1996). No hace falta ser naturalista. En España, los paisajes grotescos le han servido bien a Alex de la Iglesia, pero en el caso de la Frontera México-Estados Unidos todo parece ser una burla de algo que no existe. Dotado del dinero que le ayudaron a recabar sus dos éxitos anteriores, parece que De la Iglesia se aterrizó aquí con su propia idea de lo que es la frontera y como filmarla. Parte de su visión sobre la frontera son las violaciones placenteras para las víctimas (los dos gringos raptados: una chica y un chico son violados respectivamente por Romeo y Perdita, cumpliendo cierta igualdad bruta entre los sexos), las tomas múltiples de la misma escena y hasta la cinta adhesiva en el suelo como señales para los actores. Estos últimos trucos del director fueron muy irritantes para los actores, según Alex Cox quien tiene un papel menor en la película como policía y su crítica tiene más fuerza por ser admirador de la creatividad del director vasco. Para Cox, por muy talentoso que sea, De la Iglesia no es ningún "director de actores” (Le Cain 2003).

La falta de dirección efectiva tal vez explique la sobreactuación de los personajes principales, quienes carecen de expresión de emociones más sutiles. Los actores secundarios como Cox y James Gandolfini tenían menos presión por parte del director, por lo tanto, encontraron su trabajo más divertido, lo cual se refleja en sus actuaciones más relajadas. Otra 
de las fallas del filme es que aunque Romeo Dolorosa se describe como alguien nacido en la isla inexistente de "Petit Caribe", Javier Bardem sostiene un acento más o menos mexicano. La pena es que entre la cocaína, ultraviolencia y palabrotas al director se le olvidó parodiar algo reconocible. Hay que admitir que los distribuidores no ayudaron con el producto final: se hicieron unos 20 cortes en varios mercados para poder obtener una clasificación rentable debido a la censura o también simplemente por razones comerciales (Stevens 2000).

Si hubiera justificación artística para la náusea y sangre en este largometraje, sería que nos muestra lo hipócrita que es nuestra actitud hacia la violencia. Siendo una película seudodocumental, la violencia en Perdita Durango no es "realista" sino extrema. Y esta violencia cinematográfica permite cierta igualdad entre hombre y mujer: los actos brutales que comete Romeo también los comete Perdita. Si seguimos esta línea, sería difícil acusar a De la Iglesia de ser machista en sí: es simplemente sexo y violencia, una narrativa cuyos excesos se excusan con ironía y humor. Pero tampoco tiene el coraje de mostrarnos lo que verdaderamente pasó: Constanzo sodomizó a todas sus víctimas en Matamoros durante el acto del sacrificio. Todos hombres (Newton s.f.: 5). Una verdad tremenda que contrasta con la imagen de Estelle obteniendo placer sexual durante su violación por Romeo; a su vez, violado por Perdita, Duane tiene un orgasmo prematuro heterosexualmente provocado. Supongamos que no les habría gustado al público objetivo (masculino y joven) este aspecto de la verdad.

Vale la pena contrastar Perdita Durango con Clockwork Orange / La naranja mecánica (Kubrick 1971) o Salò (Pasolini 1975) en este sentido. Éstas dos van más allá de la ultraviolencia y decadencia sexual para plantear cuestiones tan pertinentes como incómodas sobre la cultura y la región oscura de nuestras emociones donde el poder y el dolor se encuentran con el erotismo. Ninguna de estas películas es realista, pero la visión grotesca y decadente de una Gran Bretaña futura (Naranja mecánica) o el palacio italiano en una isla de crueldad en plena Segunda Guerra mundial (Salò) tienen una resonancia cultural profunda y se vinculan con lo que sabemos de esos países y del mundo actual o de entonces, así como de nuestros temores hacia el futuro. Ambos subrayan con lógica sádica la locura inherente a la organización autoritaria (Frappier-Mazur 1996: 68-69). Perdita Durango no.

De la Iglesia desarrolla su historia en tierras fronterizas descontextualizadas y en su guión el retrato de la naturaleza humana en su estado más bruto ha de sobrevivir apoyándose solamente en su humor irónico. Pero no es suficientemente cómico tampoco. Como nota Michael Dequina (2000), el humor que le sirvió tan eficazmente a De la Iglesia en sus dos primeros largometrajes se encuentra ausente de Perdita Durango. También, pudo burlarse tanto irónicamente como eficazmente de la cultura cinematográfica de la frontera ficticia entre los Estados Unidos y México en 800 Balas, una "antipelícula" ubicada en España: se trata de actores veteranos de las películas Spaghetti Westerns italianas que luchan por su herencia en un pueblo de cine artificial. Inclusive logra crear momentos de verdadera tragicomedia.

En el caso de Perdita Durango, tal vez se debe al inglés pobre del director. Basta ver una entrevista con el de lengua anglosajona para ver que a él le falta facilidad en el inglés: hasta él mismo pide perdón (Anón 2001: "Entrevista: Alex de la Iglesia”). Los cambios bruscos entre el español y el inglés en el filme no suenan naturales sino forzados (sobre todo en la boca de un Santiago Segura frenético), y lo que se dice memorable no es de De la Iglesia. En vez de heteroglosia, el concepto Bajtiniano donde la expresión encuentra su voz en una mezcla de niveles de lengua y hasta lenguas diferentes (Bakhtin 1998: 263, 428) tenemos un guión mal escrito y muchas veces mal expresado. Malgasta su vocabulario en más de un sentido. 
En el ensayo de Simone de Beauvoir "Must we Burn de Sade?” [¿Debemos quemar a de Sade?] concluyó que:

\footnotetext{
El valor supremo de su testimonio se encuentra en su capacidad para inquietarnos. Nos obliga a reexaminar rigurosamente el problema básico que atormenta nuestra época en formas diferentes: la verdadera relación entre hombre y hombre. [Una traducción de]
}

\begin{abstract}
The supreme value of his testimony lies in its ability to disturb us. It forces us to re-examine thoroughly the basic problem which haunts out age in different forms: the true relation between man and man. (Beauvoir 1966, 64)
\end{abstract}

Salò y La naranja mecánica merecen tal descripción; Perdita Durango no. Como mínimo, De la Iglesia reconoce su debilidad filosófica potencial -tiene licenciatura en filosofía(Martínez 2002-2005). En el contexto de otra película, describe una crítica "típica" hacia su cine: "Como siempre Alex de la Iglesia se queda en la superficie, sin llegar al meollo de las cuestiones que él mismo plantea" (De la Iglesia 2005). Aparentemente, su deseo más fuerte es entretener al público, no analizar la condición humana. Según él, en la misma "autoentrevista", admite que Perdita Durango fue la película que más le gustó; es una pena que el autor de este texto como miembro del público se encuentre en desacuerdo con el director.

\title{
3. Borderland
}

La película Borderland (conocido como Al límite del terror en México) de Zev Berman (realizada en 2007; el DVD es de 2008) difiere de Perdita Durango en su tono. Borderland es una producción independiente que supera su condición para convertirse en un filme tan trascendental que es una sorpresa feliz... si usted soporta una película donde se arrancan ojos, se cortan manos y en el que se practican asesinatos rituales. A algunos críticos aparentemente les encanta y ha obtenido un resultado $100 \%$ positivo en Rottentomatoes.com de parte de críticos del género de horror, comparado con sólo 40\% para Perdita Durango, en una lista más extensa de críticos más convencionales (Anón 2009). A su manera, Zev Berman no fue ajeno a los hechos originales que se reflejan en su película. En su época de estudiante en Washington DC, él y sus amigos casi fueron arrestados cuando llegaron en la frontera en una camioneta decorada con suvenires de vudú de Nueva Orleans. Sus pertenencias los hicieron ver como satánicos justo en el momento en el que se trataba de localizar a Mark Kilroy, estudiante al igual que Berman (Berman 2008 “Inside Zev's Head”). Incluso Berman produjo un documental sobre los asesinatos de Constanzo, el cual se incluye en el DVD de su otra película (Berman 2008 "Rituales de Sangre"). Al menos conoce el terreno. Y para preparar este terreno a fin de filmar su equipo, viajó a través de muchos pueblos fronterizos antes de que él mismo eligiera los adecuados (Berman 2008 "Inside Zev's Head”). Y el esfuerzo se ve. Capturan algo del espíritu, aunque también incluyen los mismos clichés arriba notados en la cita de Castillo y Tabuenca.

En vez de recrear el final de los 80, Berman y su equipo utilizan la frontera tal como es ahora. Hay una marcha de protesta para los desaparecidos que hace eco de las marchas de protesta en, por ejemplo, Ciudad Juárez. Santillán tiene como carro ese símbolo del machismo neomilenario, un Hummer. Aquí en vez de una pareja raptada, tenemos tres estudiantes estadounidenses, quienes se ven forzados a enfrentarse efectivamente uno por uno, cada quien a su manera, con el culto santero dirigido por un tal Santillán. Henry (interpretado por Jake 
Muxworthy) es un chico fresa o pijo de la generación del Presidente Bush (hijo) cuya repugnancia y arrogancia son un gran logro para lograr ser antipático y quien es sólo uno de los tantos ejemplos de ambigüedad moral con la cual se juega en este película.

Uno de los mayores tropos (o clichés) utilizados en el arte de contar es la llegada de un(os) forastero(s) a un ambiente desconocido y amenazador. Si el forastero es del mismo origen que el público al que se dirige el mensaje, la cultura a la que llega el personaje arriesga ser retratada como inferior, a encarnar al mal comparado con el bien. Aquí los extranjeros llevan problemas previos consigo: el sacrificado, Phil, es capturado mientras alucina con hongos mágicos. (Felizmente) no vemos la sodomía como parte del sacrificio, pero el dominio que busca Santillán en todos los sentidos en el acto ritual queda patente. Revisitan el horror de The Godfather / El Padrino (Coppola 1972) con una variación propia: la víctima Anna, la "buena" santera tiene la cabeza cortada, la suya sustituida por otra, la de una cabra recién muerta. Una mala sorpresa para sus amigos. En esta narrativa hay cierta justicia hacia el espíritu de los eventos criminales que originaron la película sin pecar de mal gusto, a pesar de toda la violencia. Para Berman es importante que el espectador sepa que "se basa en hechos reales" y que se tomó el tiempo para conocer México y, aun más, que todavía vale la pena visitar el país. Al descubrir que Martha Higareda, actriz mexicana, era capaz de interpretar a un personaje mucho más fuerte que el papel femenino "típico" de victima gritona, el director sacó provecho de sus habilidades y alabó su talento (Butane s.f.).

También, hay que decir que este esquema también sigue un sendero muy desgastado, el género que Roger Ebert famosamente llama "The Dead Teenager Movie" / "El Filme de Adolescentes Muertos", donde se mueren unos estudiantes, uno tras otro, con un sobreviviente para la secuela. Los más viciosos (en términos de sexo, drogas, cinismo o simple estupidez) mueren primero (Ebert 2005, 2007, 2009). Alan Jones lo expresa más sencillamente: "ser promiscuo y morir" (2005: 43). El primero en morir entre los estudiantes de esta película es el que duerme con una prostituta, aunque en este caso el joven tiene buenas intenciones (después de descubrir que ella tiene un bebé, Phil planifica casarse con ella); Henry muere en segundo lugar, a golpe de machete, después de perder de manera rotunda su desmesurado orgullo y seguridad en sí mismo; el "héroe" Ed es el que conserva sus valores morales y el último sobreviviente, pero también es prueba de la frase de Nietzsche: "el hombre que lucha contra dragones demasiado tiempo se convierte en dragón él mismo". Al final, mata a dos de los santeros con machete y con tanta brutalidad como antes ellos habían despachado a Henry. La ventaja que tiene este largometraje es que busca nuevos ángulos desde donde retratar a los protagonistas. Como observa Joe Leydon (2007), el personaje sabe que se trata de un estereotipo y supera su condición como tal. En lugar de Viernes 13 (Jones 2005: 210-211), en el cual se enfrentan en una frontera incógnita con un monstruo igualmente desconocido (que se revela al final, naturalmente), tenemos una frontera poblada por seres humanos intentando vencer al (casi) invencible.

Otra faceta que aparta esta película de otras es el retrato de los mexicanos: los que son malvados son muy malvados; pero los buenos son fascinantes. El ex-policía Ulises, cojo y traumatizado como resultado de su tortura a manos de los seguidores de Santillán y de la muerte de su compañero también a manos de la misma secta (luego él mata a Santillán, sufriendo heridas mortales en el acto); Valeria, la novia de Ed, bilingüe y segura de sí misma; Lupe su amiga, la buena santera. 
Sin los personajes buenos de la película, la victoria contra Santillán y sus seguidores de palo mayombe no sería posible. Los policías mexicanos fronterizos no son abiertamente cínicos y corruptos, sino gente normal que tiene miedo hacia estos narcotraficantes brujos, y con razón. En contraste, el estadounidense entre los seguidores de Santillán es uno de los peores: Randall, interpretado por un Sean Astin quien no podría estar más lejos del famoso papel que desempeñó como Sam Gamgee en la trilogía de The Lord of the Rings / El Señor de los Anillos (Jackson 2001, 2002, 2003). El personaje norteamericano es asesino de varias mujeres en los EU aun antes de convertirse en "santero" al otro lado de la frontera. Randall es también uno de los seguidores de Santillán más leales y agresivos, que Berman utiliza para contradecir la noción de que Estados Unidos significa progreso, seguridad, hogar, trabajo; mientras México es el equivalente a las ideas de recreo, corrupción, extrañeza, violencia (pero que es más emocionante y sexy). Los personajes, tanto los buenos como los malos, son lo suficientemente ambiguos para despertar el interés del espectador. Los bondadosos no son tan buenos y los malos son "redondos" incluso en sus momentos más maléficos. Como describe Lupe a los seguidores, ellos ni siquiera creen que tienen alma y eso les permite actos de violencia desenfrenada. No obstante, al final, los seguidores mueren como humanos, no como diablos.

Los protagonistas empiezan la película como (para emplear la distinción de E.M. Forster 1956: 65-82) personajes planos y la terminan como personajes (hasta personas) redondos, con una razón de ser. Esta es una película de horror (así se anuncia en el empaque del DVD) donde tres estudiantes americanos cruzan la frontera para divertirse (para citar a Vila otra vez, en la tierra de los libertin@s (2007: 181-208)) y sabemos que antes del final casi seguramente dos van a morir a manos de unos malvados, antes de que el sobreviviente termine por impartir una justicia mortal a los antagonistas perversos. Este reparto y la manipulación hábil de la trama genérica y tradicional salvan la película de ser una lucha de la civilización americana contra barbarie mexicana: en todo caso, la película propone que la barbarie es de todos; es sencillamente más fácil ser bárbaro en México si uno tiene dinero del primer mundo dentro de una economía tercermundista.

Igualmente, hay que reconocer el mérito de la cinematografía. En un mundo donde la serie Bourne (Liman 2002) y The Blair Witch Project / El proyecto Blair Witch (Myrick, Sánchez 1999) han convertido shakycam en el truco más recurrido del nuevo milenio, Berman y sus camarógrafos emplean una variedad de estilos para indicar estrés, desorientación, acción y la experiencia de ver el mundo en un estado mental provocado por las drogas. Todos los recursos se equilibran al intercalarse con tomas más convencionales para que el auditorio no se maree ni se harte. Bastan, no sobran. Como nota el director (Berman 2008 "Inside Zev's Head"), no tenían el dinero para sangre o otros efectos costosos generados por computadora: lograron milagros con el líquido rojo tradicional, o manipulando la lente de la cámara en las escenas "drogadas" de la feria para generar manualmente efectos fantasmagóricos. Y para retratar la frontera, empleó a un departamento de arte casi hispano por completo.

En el transcurso de mi investigación sobre Constanzo, sobre las muertes de Juárez, así como de las nuevas encarnaciones de la Llorona, he visto varias películas de violencia fronteriza con presupuestos altos -Bordertown / Pueblo fronterizo (Nava 2006)- y bajos -Borderline Cult / Culto de la línea fronteriza (Lommel 2007)-. Entre las películas que he visto hay hasta la de los adolescentes estadounidenses muertos que visitan México -The Wailer / La Llorona (Navia 2006) - y una larga lista de etcéteras cinematográficas, tanto de México como de los Estados Unidos. Borderland es la mejor. 


\section{Conclusión}

Hay que admitir que la versión de santería aquí en estas películas debe algo a Hollywood. Los cubanos que prestaron su imagen a la santería en el pensamiento popular -cantantes como Celia Cruz, Desi Arnaz, Ibrahim Ferrer o los creadores del filme Fresa y chocolate (Gútierrez Alea, Tabío 1994) - son muy difíciles de reconciliar con la seudo-santería de estas dos películas. La verdad de Constanzo mismo se inspiró en una película para lograr su mezcla de santería y palo mayombe. Sabía emplear las ténicas del teatro y las utilizaba en forma sangrienta para quitarles el dinero a ciertos narcos supersticiosos y para controlar a sus seguidores. Constanzo usaba videocasetes de la película de John "Midnight Cowboy" Schlesinger, The Believers / Los creyentes (1987) para convencer a la gente que la santería funcionaba de manera fulminante y poderosa (Provost 1989: 128-129, 136). En esta última película, el mexicano-americano Charlie Sheen (quien interpreta a un protagonista anglosajón) y el puertorriqueño Jimmy Smits despliegan todos sus poderes de sobreactuación para convencernos que los inmigrantes han traído a Nueva York una religión que tiene el poder de enloquecer a las personas, hacer crecer serpientes en el estomago o provocar la explosión de arañas en un grano de la cara... o darle a alguien todo el éxito material que desee, a precio del sacrificio humano del hijo. Sara Aldrete había visto el filme antes de mostrarla a Constanzo, y ella lo empleó una y otra vez como útil de reclutamiento y entrenamiento para los miembros del culto (Schutze 136-138).

Observa Provost que The Believers / Los creyentes ni es sofisticada ni fidedigna en su retrato de santería (1989: 129). En este caso, el hijo fue interpretado por Harley Cross, quien también encarna a Duane, de manera similar casi sacrificado en la película Perdita Durango. Si Alex de la Iglesia y Constanzo tienen algo en común, es que su visión de la espiritualidad se basa más en el teatro violento y externalizado de Hollywood que en la fe de la grandísima mayoría de santeros, vuduistas y curanderos o hasta de de los seguidores de palo mayombe. Por el contrario, Berman en Borderland reconoce que el mundo no se pinta en blanco y negro teniendo, además, otra ventaja: supo utilizar los recursos que tenía a su disposición. Sí, su filme es violento y con ciertos toques eróticos. Igualmente, son así muchas películas que tratan el mismo y otros temas: buenas, malas y simplemente regulares. Lo que distingue Borderland de Perdita Durango, aunque también sabe a sangre, es que Borderland trata de reconstruir al México de México, no al de Hollywood.

Hay otras historias fronterizas aparte de las sangrientas y morbosas que merecen contarse y se han contado en películas tales como Santitos (Springall 1999) o Como agua para chocolate (Arau 1992), con sus protagonistas fuertes, femeninas y mexicanas, y su realismo mágico. Lo que hace Borderland es mostrar a su auditorio, que suponemos es un público estadounidense, algunos ejemplares del horror "mexicano" a fin de subrayar inmediatamente después que esta frontera de cristal no es nada más que un espejo. Como dice el mismo Berman, su deseo es que miremos lo que hay dentro de nosotros todos (Butane s.f.).

\section{Notas}

1. Tal cosa no quiere decir definitivamente que se trata de satanismo. Hay que acordarse de que el rito católico incluye el milagro de la transubstanciación, seguido por el consumo de "sangre" y "carne", y que muchas veces hay restos humanos visibles en la iglesia, que en ciertas ocasiones hasta forman parte del rito religioso. Eso no quiere decir que el rito católico se trate de magia negra. La cuestión de robo 
de tumbas sí que es repugnante tanto como el uso de huesos sin el consentimiento ni del difunto ni de la familia, pero en los EU se pueden obtener huesos, calaveras y hasta esqueletos humanos enteros de modo perfectamente legal, por unos cientos de dólares. Véase Anón. 2009. The Boneroom: A Natural History Store. http://www.boneroom.com/bone/humanskeletons.htm. Consulta: 15 diciembre 2009.

\section{Bibliografía}

Anón. 2001. "Interview: Alex de la Iglesia". El día de la bestia. DVD: Alemania Anolis Entertainment.

Anón. IMDB / The Internet Movie Database. http://www.imdb.com/. Consulta: 10 de noviembre de 2009.

Anón. 2009. Rotten Tomatoes. http://www.rottentomatoes.com/m/10008140-borderland/ \& http://www.rottentomatoes.com/m/dance_with_the_devil/. Consulta: 10 de noviembre de 2009.

Anón. 1996. "Saguaro Cactus". Desert USA: The Ultimate Desert Resource. http://www. desertusa.com/july96/du_saguaro.html. Consulta: 06 de septiembre de 2009.

Applebome, Peter. 1989. "Drugs, Death and the Occult Meet In Grisly Inquiry at Mexico Border". The New York Times. http://www.nytimes.com/1989/04/13/us/drugsdeath-and-the-occult-meet-in-grisly-inquiry-at-mexico-border.html. Consulta: 09 de noviembre de 2009.

Arau, Alfonso (dir). 1992. Como agua para chocolate. México: Miramax Films.

Associated Press (AP). 1989. "Leader in Cult Slayings Ordered Own Death, Two Companions Say". The New York Times. http://www.nytimes.com/1989/05/08/us/leader-in-cultslayings-ordered-own-death-two-companions-say.html. Consulta: 09 noviembre, 2009.

Bakhtin, M. 1998. The Dialogic Imagination. Austin: University of Texas Press.

De Beauvoir, Simone. 1966. "Must we burn de Sade?" (trad. de A. Michelson). En: Donatien Alphonse François de Sade.

Bell, Rachael; Marlyin Beardsley. s.f. "Ed Gein". truTV.com. http://www.trutv.com/library/ crime/serial_killers/notorious/gein/bill_1.html. Consulta: 09 de noviembre de 2009.

Berman, Zev (dir). 2008. Borderland [parte de la serie After Dark Horrorfest]. EU/México: Lions Gate. DVD.

2008. "Inside Zev’s Head". Borderland. EU/México: Lions Gate. DVD. 
2008. "Rituales de Sangre" Borderland. EU/México: Lions Gate. DVD.

Bolívar Aróstegui, Natalia Y Carmen González Díaz de Villegas. 1998. Ta makuende yaya y las reglas de palo monte. Ciudad de La Habana: Ediciones Unión.

Butane, Johnny. s.f. Dread Central.com. http://www.dreadcentral.com/interviews/berman-zevborderland. Consulta: 09 de noviembre de 2009.

Le Cain, Maximilian. 2003. "Interview with Alex Cox and Tod Davies." Senses of Cinema. http://archive.sensesofcinema.com/contents/03/24/cox_davies.html. Consulta: 6 de setiembre de 2009.

Castillo, Debra y María Socorro Tabuenca. 2002. Border Women: Writing from La Frontera. Minneapolis / London: University of Minnesota Press.

Coppola, Francis Ford, dir. 1972. The Godfather: EU: Paramount Pictures.

Craven, Wes, dir. 1988. The Serpent and the Rainbow: EU: Universal Pictures.

Myrick, Daniel y Eduardo Sánchez (dir). 1999. The Blair Witch Project. EU: Artisan Entertainment.

Demme, Jonathon (dir). 1991. The Silence of the Lambs. EU: Orion.

Dequina, Michael. 2000. “Dance with the Devil”. The Movie Report Archive. 70: 239-240. http:// mrbrownmovies.com/movierpt70.html\#devil. Consulta: 09 de noviembre de 2009.

Ebert, Roger. 2005. "House of Wax". Chicago Sun-Times. http://rogerebert.suntimes.com/apps/pbcs. dll/article?AID=/20050505/REVIEWS/50426003. Consulta: 09 de noviembre de 2009.

2007. "Dead Teenage Wasteland". Chicago Sun-Times. http://rogerebert.suntimes.com/apps/ pbcs.dll/article?AID=/20070629/ANSWERMAN/307. Consulta 09 de noviembre de 2009.

2009. "Ebert's little movie glossary". Chicago Sun-Times. http://rogerebert.suntimes. com/apps/pbcs.dll/classifieds?category $=$ search $1 \&$ SearchType $=1 \&$ Class $=62 \&$ FromDate $=19150101 \&$ ToDate=20091231\&SortOrder=Title. Consulta: 09 de noviembre de 2009.

Forster, E. M. 1956. Aspects of the novel. Orlando: Harcourt.

Frappier-Mazur, Lucienne. 1996. Writing the Orgy: Power and Parody in Sade. Philadelphia: University of Pennsylvania Press.

Gifford, Barry. 1996. Perdita Durango. New York: Grove Press. 
González-Whippler, Migene. 1990. Santería: magia Africana en Latinoamérica. Plainview: New York.

Gutiérrez Alea Tomás y Juan Carlos Tabío (dir). 1994. Fresa y chocolate. Cuba: ICAIC / Miramax.

Halperin, Victor (dir). 1932. White Zombie. EU: United Artists.

Hitchcock, Alfred (dir). 1960. Psycho. EU: Paramount Pictures.

Hooper, Tobe (dir). 1974. The Texas Chainsaw Massacre. EU: Bryanston Distributing.

De la Iglesia, Alex. 1999. Perdita Durango. DVD. España/EU/México: A-PIX Entertainment.

De la Iglesia, Alex. 2005. "Autoentrevista demencial". Página oficial de Alex de la Iglesia http://www.clubcultura.com/clubcine/clubcineastas/delaiglesia/entrevista01.htm. Consulta: 06 de setiembre de 2008.

Jackson, Peter (dir). 2001. The Lord of the Rings: The Fellowship of the Ring. Nueva Zelanda/ EU: New Line Cinema.

2002. The Lord of the Rings: The Two Towers. Nueva Zelanda/EU: New Line Cinema. 2003. The Lord of the Rings: The Return of the King. Nueva Zelanda/EU: New Line Cinema.

Jones, Alan. 2005. The Rough Guide to Horror Movies. London: Rough Guides Ltd.

Kubrick, Stanley (dir). 1971. Clockwork Orange. Reino Unido/EU: Warner Bothers.

Land, Stephen; Zak Weisfield, prds. 2008. Adolfo Constanzo: The Godfather of Matamoros. Bio The Biography Channel. http://www.imdb.com/video/hulu/vi690225689/. Consulta: 15 de setiembre de 2009.

Leone, Sergio (dir). 1966. El bueno, el malo y el feo. Alemania/España/Italia: United Artists.

Leydon, Joe. 2007. "Borderland”. Variety. http://www.variety.com/review/VE1117933366. html?categoryid=31\&cs=1. Consulta: 09 de noviembre de 2009.

Liman, Doug (dir). 2002. The Bourne Identity. EU: Universal Pictures.

Lommel, Ulli (dir). 2007. Borderline Cult. DVD. EU: Lionsgate. 
Lynch, David (dir). 1990. Wild at Heart. EU: The Samuel Goldwyn Company.

Martinez, Arianna. "Alex de la Iglesia: An Interview with Spain's Most Popular Film-Maker". The Blow Up: The Web Magazine Archives (2002-2005) http://www.theblowup.com/ archived/alexisdelaiglesia/. Consulta: 06 de setiembre de 2009.

Nava, Gregory (dir). 2006. Bordertown. EU: THINKFilm.

Navia, Andrés (dir). 2006. The Wailer. DVD. EU: Laguna Productions.

Newton, Michael (dir). s.f. “Adolfo Constanzo”. truTV.com. http://www.trutv.com/library/ crime/serial_killers/weird/constanzo/1.html. Consulta: 09 de noviembre de 2009.

Parker, Alan (dir). 1987. Angel Heart. EU: TriStar Pictures.

Pasolini, Pier Paolo (dir). 1975. Salò: o le 120 giornate di Sodoma / Salò: 120 days of Sodom. Italia: United Artists Europa.

Provost, Gary. 1989. Across the Border: The True Story of the Satanic Cult Slayings in Matamoros, Mexico. New York: Pocket Books.

De Sade, Donatien Alphonse François (Marquis de Sade). 1966. 120 Days of Sodom and other Writings. Comp. and trans. A. Wainhouse and R. Seaver. New York: Grove Press.

Schlesinger, John (dir). 1987. The Believers. EU: Orion.

Shutze, Jim. 1989. The Matamoros Cult Killings. New York: Avon Books.

Springall, Alejandro (dir). 1999. Santitos. México: New Yorker Films.

Stevens, Brad. 2000 “Perdita Durango, a Case Study”. Senses of Cinema. http://archive.sensesofcinema.com/contents/00/5/perdita.html. Consulta: 06 de septiembre de 2008.

Tourneur, Jacques. 1943. I Walked with a Zombie. EU: RKO Radio Pictures.

Victor, Jeffrey S. 1996. Satanic Panic. Chicago and La Salle: Open Court.

Vila, Pablo. 2007. Identidades fronterizas: Narratives de religión, género y clase en la frontera México-Estados Unidos. Ciudad Juárez, El Colegio de Chihuahua / Universidad Autónoma de Ciudad Juárez: Colección sin fronteras. 